\title{
Vivências de homens acompanhantes de puérperas internadas na unidade de terapia intensiva por síndrome hipertensiva
}

\author{
Experiences of men accompanying puerperal women hospitalized in the intensive care unit due to \\ hypertensive syndrome
}

Experiencias de hombres que acompañan a puérperas internadas en unidades de cuidados intensivos por síndrome hipertensivo

\section{Marianna dos Santos AraújoI, Mônica Cecília Pimentel de MeloII, Lucivânia de Oliveira Costa ${ }^{\mathrm{III}}$ Lucineide Santos Silva Viana ${ }^{\mathrm{IV}}$, Yane Tina Macêdo Pinto Santanav}

Resumo: Objetivo: analisar as vivências dos homens acompanhantes de puérperas internadas na unidade de terapia intensiva por síndrome hipertensiva gestacional. Método: estudo exploratório descritivo, de abordagem qualitativa, realizado em um hospital materno-infantil público de Petrolina, Pernambuco. Foram entrevistados oito homens que acompanhavam no puerpério sua companheira internada. Os dados foram submetidos à análise temática de conteúdo. Resultados: os participantes experienciaram dificuldades de comunicação com os profissionais da saúde e não compreendiam as condições de saúde e os riscos de complicações. A preocupação com o parto e as oscilações da pressão arterial permeavam o cuidado prestado pelos homens. Conclusão: a hospitalização modificou o ritmo familiar, sendo inevitável o auxílio de uma rede de apoio para compartilhar as dificuldades e tarefas que são demandadas durante esse momento. Os profissionais, principalmente enfermeiros obstetras, devem incentivar a vinculação do parceiro e elaborar estratégias educacionais para sua participação ativa durante o período gravídico-puerperal.

Descritores: Hipertensão Induzida pela Gravidez; Pré-eclâmpsia; Eclâmpsia; Enfermagem Obstétrica; Paternidade

\footnotetext{
${ }^{\text {I }}$ Enfermeira. Especialista em Saúde da Família pela UNIVASF. Especialista em Obstetrícia pela Residência em Enfermagem Obstétrica do Hospital Dom Malan/IMIP. Petrolina, Pernambuco, Brasil. E-mail: mariannasaraujo@hotmail.com Orcid: https://orcid.org/0000-0001-7301-7506

II Enfermeira. Doutora em Educação em Ciências, Química da Vida e Saúde com Associação entre UFRGS/UFSM/FURG. Mestre em Enfermagem na Atenção à Saúde da Mulher - UFBA. Prof ${ }^{a}$ da UNIVASF - Enfermagem em Saúde da Mulher e Gênero e Manejo da Amamentação. Petrolina, Pernambuco, Brasil. E-mail: monquinamelo@gmail.com; monica.cecilia@univasf.edu.br Orcid: http://orcid.org/0000-0003-4029-4886

III Enfermeira. Especialista em Obstetrícia. Universidade do Estado da Bahia - UNEB. Afrânio, Pernambuco, Brasil. E-mail: vanniaoc@gmail.com Orcid: https://orcid.org/0000-0001-7318-2253

IV Enfermeira. Doutoranda em Ciências pela Fundação Antônio Prudente/AC Camargo, área de concentração Oncologia. Mestra em Enfermagem na Atenção à Saúde da Mulher-UFBA. Docente do Colegiado de Enfermagem da Universidade Federal do Vale do São Francisco- PE, Brasil. Área de atuação Saúde da Mulher e Gênero. E-mail: enflucineide@hotmail.com; lucineide.silva@univasf.edu.br Orcid: https://orcid.org/0000-0003-4313-5231

V Enfermeira. Especialista em Qualidade e Segurança no Cuidado ao Paciente pelo Hospital Sírio-Libanês, São Paulo, Brasil. Especialista em Enfermagem Obstétrica pela Rede Cegonha, Minas Gerais, Brasil. Hospital Dom Malan. Petrolina, Pernambuco, Brasil. E-mail: yanemacedo3@hotmail.com Orcid: https://orcid.org/0000-0001-6736-9935
} 
Abstract: Objective: to analyze the experiences of men accompanying puerperal women hospitalized in the intensive care unit due to gestational hypertensive syndrome. Method: a descriptive an exploratory study with a qualitative approach, conducted in a public maternal-child hospital of Petrolina, Pernambuco. Eight men accompanying their hospitalized partners during the puerperium were interviewed. The data were submitted to thematic content analysis. Results: the participants experienced difficulties communicating with the health professionals and did not understand the health conditions and the risks of complications. Concern with delivery and the fluctuations in blood pressure permeated the care provided by the men. Conclusion: hospitalization modified family pace, the aid of a support network being unavoidable to share the difficulties and tasks required during this period. The professionals, especially the obstetric nurses, must encourage the partner's bonding and devise educational strategies for their active participation during the gestational-puerperal period.

Descriptors: Hypertension, Pregnancy-Induced; Pre-eclampsia; Eclampsia; Obstetric nursing; Paternity

Resumen: Objetivo: analizar las experiencias de los hombres que acompañan a mujeres puérperas internadas en unidades de cuidados intensivos por síndrome hipertensivo gestacional. Método: estudio exploratorio y descriptivo, con enfoque cualitativo, realizado en un hospital materno-infantil público de Petrolina, Pernambuco. Se entrevistó a un total de ocho hombres que acompañaban a sus parejas internadas durante el puerperio. Los datos fueron sometidos a análisis temático de contenido. Resultados: los participantes tuvieron dificultades de comunicación con los profesionales de la salud y no comprendieron el estado de salud y los riesgos de complicaciones. La preocupación por el parto y las fluctuaciones en los valores de presión arterial se hizo presente en la atención prestada por los hombres. Conclusión: la internación modificó el ritmo familiar, siendo inevitable la asistencia de una red de apoyo para compartir las dificultades y tareas que son necesarias durante este período. Los profesionales, principalmente los del área de Enfermería Obstétrica, deben incentivar la vinculación de la pareja de la mujer embarazada y diseñar estrategias educativas para su participación activa durante el período de embarazo-puerperio.

Descriptores: Hipertensión Inducida en el Embarazo; Preeclampsia; Eclampsia; Enfermería Obstétrica; Paternidad

\section{Introdução}

A experiência da parentalidade vivenciada por mulheres e homens durante o percurso da gravidez até o nascimento da criança gera diferentes sentimentos devido a uma construção psíquica/psicológica singular, consciente e inconsciente para recepcionarem o bebê que está a caminho. Diante de todas as transformações fisiológicas ocorridas na gestação, o casal precisa adaptar-se a este novo momento de instabilidade emocional e, muitas vezes, ficam diante de uma ambivalência afetiva que perpassa por sentimentos como medos, dúvidas e angústias. ${ }^{1}$

Logo, a gravidez é um fenômeno fisiológico com modificações iniciadas desde a primeira semana até ao final da gestação e, em sua maioria, ocorrem sem distócias. Entretanto, parte das gestantes pode desenvolver intercorrências e complicações nesse período e a pré-existência de 
alguma situação de doença ou agravo pode favorecer um seguimento desfavorável, gerando riscos e/ou sequelas maternas e fetais. Essas condições de desequilíbrio necessitam de maior atenção e acompanhamento, sendo então denominadas de gestações de alto risco. ${ }^{2}$

Entre as situações que levam a classificar uma gestação de alto risco destacam-se as Síndromes Hipertensivas na Gestação (SHGs) que são responsáveis por aproximadamente 14\% das mortes maternas no mundo e $22 \%$ na América Latina, ocupando o segundo lugar no ranking de causas de óbitos maternos. Ressalta-se que $10 \%$ de todas as gestações no mundo evoluem com algum distúrbio hipertensivo multissistêmico, sendo classificados em pré-eclâmpsia, eclâmpsia, hipertensão arterial crônica (de qualquer causa), hipertensão crônica com pré-eclâmpsia superajuntada e hipertensão gestacional. ${ }^{1-3}$

Entre os anos de 1996 a 2018, as síndromes hipertensivas ocasionaram 8.186 óbitos, representando a maior causadora de mortes maternas no Brasil, sendo destaque juntamente com as demais causas obstétricas diretas: hemorragia (5.160 vidas perdidas), infecção puerperal (2.624 mortes) e aborto (1.896 falecimentos). ${ }^{4}$ Elas são a primeira causa de mortalidade materna no país, bem como as maiores responsáveis pelo alto índice de perdas perinatais e de neonatos com sequelas, por vezes devido a situações como prematuridade e crescimento intrauterino restrito, além de outras complicações como o descolamento prematuro de placenta. ${ }^{1-2}$

Nessa perspectiva, o agravamento das SHGs, sobretudo as repercussões maternas da préeclâmpsia, predispõem a mulher a uma sobrecarga emocional que pode suscitar ansiedade, dependência, depressão e medo, agravado pela inevitável hospitalização materna, repouso e posterior interrupção da gravidez. Esses eventos modificam toda a sequência natural do nascimento e alteram o ritmo de toda a rede familiar. Em vista disso, a humanização da assistência por parte do profissional de saúde, em particular do enfermeiro obstetra, deve priorizar a individualidade dessa gestante de modo que sua família seja bem orientada e inserida nesse processo saúde-doença, colaborando para uma atenção horizontalizada e responsável. ${ }^{5}$ 
Vivências de homens acompanhantes de puérperas internadas na unidade de terapia... | 4

Com o intuito de minimizar essa problemática e favorecer a inserção da família nesse caminho para o nascimento, baseando-se nas recomendações da Organização Mundial da Saúde (OMS) e do Programa de Humanização no Pré-natal e Nascimento, a Lei Federal no 11.108/2005, determina que os serviços de saúde são obrigados a permitir a parturiente o direito à presença de um acompanhante, indicado por ela, durante todo o trabalho de parto, parto e pós-parto imediato. Atrelado a isso, é preconizado o acolhimento humanizado por parte do profissional de saúde que prestará assistência à paciente e ao seu acompanhante, podendo ser o pai da criança, o parceiro atual, a mãe ou outra pessoa de sua livre escolha. O incentivo a essa presença, além de possibilitar um melhor atendimento à mulher, favorece o vínculo entre parceiro e bebê, diminui o medo e a tensão, favorece o aleitamento materno, dentre outros benefícios. ${ }^{6}$

Sabe-se que as configurações familiares não tradicionais existentes, a paternidade e o conceito de família vão além dos aspectos biológicos e de consanguinidade, pois a sua conformação depende das interações, vivências, afinidades e sentimentos estabelecidos entre cônjuges, genitores, filhos, tipo de união e tamanho da família. Assim, essa vinculação entre a criança e a figura paterna pode ocorrer independente de ser ou não pai biológico, de sexo e/ou de algum laço de parentesco. ${ }^{7}$ Nesse tocante, observa-se que nas últimas décadas, gradativamente, o homem tem demonstrado uma maior participação, interação e envolvimento na vida e nos cuidados com sua família, ocupando assim, um papel diferente em relação à paternidade. ${ }^{8}$

Nessa conjuntura, quando a parceira apresenta diagnóstico que revela risco à saúde, o seu companheiro também experimenta momentos de angústia e temor. Entretanto, na maioria das vezes, o cônjuge reprime suas emoções, pois não apresenta espaço para sanar suas dúvidas e inseguranças dentro da rede de cuidados voltados à gestante, sobretudo no que diz respeito às SHGs. Fazem-se necessários profissionais de saúde sensibilizados que voltem à atenção ao parceiro e que contemplem por meio do amparo, do acolhimento e da educação em saúde as suas possíveis dúvidas e ansiedades, garantindo assim, seu direito reprodutivo. ${ }^{5}$ 
Nesse cenário, destaca-se o papel do enfermeiro, especialmente o obstetra, que deve oportunizar ao casal, momentos de cunho educativo e assistencial, acolhendo ambos durante todo o pré-natal, parto, pós-parto e nos cuidados com o recém-nascido, por meio de uma comunicação efetiva tornando-os protagonistas do processo de gestar. ${ }^{5}$ Portanto, espera-se que reflexões sobre o parceiro no contexto da gestação de alto risco possam contribuir para sensibilização de novas práticas humanizadas de atuação do enfermeiro obstetra frente ao homem, acolhendo-o, viabilizando o seu reconhecimento como ator importante nesse processo de cuidado voltado para a tríade mãe-pai-filho.

Partindo-se do pressuposto de que uma mulher grávida acometida pelo agravamento de alguma síndrome hipertensiva pode trazer inúmeras preocupações, inquietações e novas responsabilidades, sobretudo para o seu parceiro, faz-se pertinente responder à seguinte questão de pesquisa: quais as vivências dos homens acompanhantes de puérperas internadas na unidade de terapia intensiva por síndrome hipertensiva gestacional? Em vista disso, a presente pesquisa delimita como objetivo analisar as vivências dos homens acompanhantes de puérperas internadas na unidade de terapia intensiva por síndrome hipertensiva gestacional.

\section{Método}

Trata-se de um estudo exploratório descritivo, de abordagem qualitativa, desenvolvido na Unidade de Terapia Intensiva (UTI) Obstétrica de um hospital materno-infantil público do município de Petrolina no Estado de Pernambuco, referência para gestação e parto de alto risco. Nesta UTI existem dez leitos, sendo um isolamento, e teve uma média de 110 novas admissões por mês. Esta instituição presta serviço às mulheres usuárias do Sistema Único de Saúde por demanda espontânea e/ou por Central de Regulação Interestadual de Leitos (CRIL) que regula os leitos da Rede Interestadual de Atenção à Saúde do Vale do Médio São Francisco (Rede PEBA). Essa Rede compõe a Macrorregião Interestadual do Vale Médio do São Francisco, compreendendo 53 municípios e uma população de aproximadamente 1,8 milhão de habitantes. ${ }^{9}$ 
Vivências de homens acompanhantes de puérperas internadas na unidade de terapia... $\mid 6$

Os participantes do estudo foram oito homens acompanhantes do(a) recém-nascido e de suas companheiras, durante internação nesta UTI. Todas as mulheres tinham hipótese diagnóstica de síndromes hipertensivas na gestação. Não existiram recusas quanto à colaboração com o estudo.

Para facilitar a seleção, foram estabelecidos os critérios de inclusão: a) ser do sexo masculino; b) possuir vínculo afetivo com a mulher internada, independente de ser ou não o pai biológico; c) ser acompanhante do recém-nascido, cuja mãe estava internada em UTI; d) realizar visita à UTI Obstétrica durante o período de internação da sua companheira. Foram excluídos os casos em que os homens eram menores de 18 anos e aqueles que estavam apenas visitando os recém-nascidos.

Esta pesquisa foi constituída por uma amostra não probabilística, do tipo intencional, pois abrangeu um segmento específico de público escolhido previamente pelo pesquisador. O número de participantes decorreu de um fechamento por exaustão já que foram incluídos oito indivíduos elegíveis e disponíveis para colaborarem durante o período da coleta. ${ }^{10}$

Os dados foram obtidos por meio de entrevistas semiestruturadas, entre novembro de $2018 \mathrm{e}$ janeiro de 2019, com auxílio de gravador de áudio, após diálogo prévio com os colaboradores do estudo. Os participantes foram convidados a participar da pesquisa logo após uma abordagem inicial sobre o tema e as entrevistas foram realizadas na mesma oportunidade pela pesquisadora responsável em uma sala privada cedida pela coordenação de enfermagem do hospital. Para essa finalidade, utilizou-se um instrumento direcionador da coleta do material empírico, que favoreceram ao participante expor suas experiências durante o período de internação de sua parceira. Este instrumento solicitava dados sociodemográficos para identificação, hipótese diagnóstica da parceira e continha os seguintes questionamentos: Você foi informado por algum profissional de saúde sobre a situação de sua companheira? Você sabe me dizer qual profissional te repassou informações sobre o estado de saúde de sua companheira? Você sabe por que sua companheira está internada na UTI desse hospital? Me explique. Como está sendo para você cuidar da sua companheira e da criança (facilidades e dificuldades)? Como você se sente com tudo isso? 
O material empírico obtido das entrevistas foi tratado por meio da Análise Temática de Conteúdo que se desenvolveu em três fases operacionais. A primeira foi a pré-análise que se subdividiu nas etapas: leitura flutuante do material transcrito, constituição do corpus, formulação e reformulação de hipóteses e objetivos. $\mathrm{Na}$ segunda fase foram explorados os dados obtidos para posterior etapa final: tratamento dos resultados obtidos e interpretação. Nessa última fase foram apreendidos conteúdos relevantes ao objeto de estudo, aparentemente oculto nos discursos. ${ }^{11}$

As entrevistas ocorreram após aprovação pelo Comitê de Ética em Pesquisa em Seres Humanos do Instituto de Medicina Integral Prof. Fernando Figueira (CEP-IMIP) em 24 de outubro de 2018, sob nº de parecer/protocolo 2.979.373. A pesquisa foi conduzida de acordo com os padrões éticos exigidos (Resoluções 466/2012 - 510/2016 - 580/2018, do Ministério da Saúde) e após a assinatura do Termo de Consentimento Livre e Esclarecido por todos os participantes. Com o intuito de garantir o anonimato dos homens, eles foram identificados na pesquisa por meio da letra H seguido do número referente à ordem de realização das entrevistas.

\section{Resultados}

Com relação à caracterização dos participantes envolvidos no estudo, cinco encontravam-se na faixa etária entre 26 a 35 anos, um tinha entre 18 a 25 anos e dois estavam com idade superior a 35 anos. Quanto ao nível de escolaridade, dois dos entrevistados possuíam ensino médio completo, quatro não concluíram o ensino fundamental e dois consideravam-se analfabetos. Nenhum dos participantes era graduado ou estava em algum curso de nível superior. Além disso, no quesito cor, três participantes se autodeclaravam pardos, dois brancos e três pretos. A maioria (seis) tinha a renda familiar de 01 a 02 salários mínimos e dois participantes relataram uma renda menor que 01 salário mínimo. Três depoentes eram casados, dois solteiros e três viviam em união estável. Todos relataram serem pais biológicos dos recém-nascidos.

Da análise das entrevistas emergiram quatro categorias: "Ausência de informação sobre a 
Vivências de homens acompanhantes de puérperas internadas na unidade de terapia... $\mid 8$

situação de saúde de sua companheira"; "Cuidados prestados pelos acompanhantes e seu enfrentamento diante da mulher hospitalizada"; "Cuidados com o recém-nascido frente às relações de gênero”; e, “Enfrentamentos dos homens durante o processo de internação da puérpera”.

\section{Ausência de informação sobre a situação de saúde de sua companheira}

$\mathrm{Na}$ análise dos relatos percebeu-se que devido a dificuldades de comunicação entre profissionais de saúde e familiares, os entrevistados não compreendiam as reais condições de saúde de suas companheiras que vivenciavam uma gestação de alto risco. Por meio dos depoimentos, nota-se que alguns homens receberam informações superficiais vindas apenas da própria puérpera, tornando difícil o entendimento da situação e seus riscos.

Não, nenhum. Só sei o que minha mulher contou. (H02)

Explicou quando ela estava já na UTI, o restante, ela [companheira] que estava repassando para mim. Porque me deixaram entrar quando ela foi internada. Mas a única coisa que eu sabia era o que ela me disse. Que ela estava com a pressão alta, iria tomar um medicamento para normalizar a pressão e tentar parir normal. (H06)

Não. Então, foi uma das coisas que eu achei assim [pausa] ficou tudo muito sigiloso. Eu como acompanhante dela, esposo dela. Tudo bem que eu não poderia ter acesso ao local que ela estava. Mas, alguma informação, eu acharia que seria relevante. Porque eu fiquei na cadeira em frente [ao bloco cirúrgico] de umas quatro horas da tarde até umas seis e pouco. Fiquei mais de duas horas sentado sem informação. Foi quando veio uma pessoa para levar ela para UTI e eu fiquei com a criança. Quando eu perguntei a ela sobre minha esposa, eu falei o nome e ela só balançou a cabeça e passou. Não deu informação nenhuma. (H05)

Corroborando essa mesma dificuldade de comunicação, outros homens acompanhantes, quando questionados se haviam sido informados sobre a situação de saúde de suas parceiras relataram que receberam informações superficiais ou pouco detalhadas dos profissionais de saúde que prestaram assistência. Percebeu-se pelos relatos que o parceiro chegou ao serviço acompanhando a sua mulher, porém com o desenrolar da assistência e falhas na comunicação não 
esteve presente no momento do parto.

Não. Eu vim com ela na maca, aqui para sala de parto, mas foi cesáreo porque não tinha dilatação. Depois eu voltei umas nove horas da noite e o bebê já tinha nascido. [...] Eu a vi saindo na maca e só disseram que ia levar para UTI tomar um medicamento. Mas não disseram o motivo. (H01)

Não. Só agora que fiquei sabendo que ela iria para UTI, porque a pressão subiu. Até o momento, só isso. (H04)

Observa-se que os homens não demonstraram compreender claramente qual havia sido, de fato, o seguimento dado após a companheira ser internada no serviço. Essa ausência de informações pode gerar sentimentos de ansiedade, estresse, insegurança ou medo de que alguma complicação ocorra com o bebê ou com a mãe durante esse distanciamento.

\section{Cuidados prestados pelos acompanhantes e seu enfrentamento diante da mulher hospitalizada}

Quando questionados sobre como estava sendo para cuidar da sua companheira, os homens demonstraram preocupação com relação ao tipo de parto, quanto ao parto antes da data provável e ao medo devido às oscilações de pressão arterial. Os relatos refletem que a percepção de cuidado identificada pelos parceiros se resumia aos sentimentos ou aflições que estavam experenciando. Outros acompanhantes referiram realizar ações voltadas para o cuidado direto da puérpera e quando exemplificado remetiam apenas a ajuda durante o posicionamento/locomoção no leito.

A preocupação maior foi porque eu já vim preocupado de lá [do município natal] por causa dos batimentos da criança e com a pressão dela também. [...] Era para ter mais um auxílio para ajudar a pessoa que está acompanhando ela. Para não ficar pensando algo. Podia ser até estava tudo tranquilo lá, só que eu não vou adivinhar ou imaginar. (H05)

Era para nascer hoje, só que não deu e nasceu ontem [...]. Já estava tudo certo para nascer normal, mas disseram que tinham que fazer a cesárea, não sei o porquê [...]. Mas a pressão só oscilava. Não regula não, a pressão dela é alta direto. (H02)

Está sendo uma experiência. Por que como foi cesáreo, ela não pode se mover muito e eu tenho que ajudar. Porque naquela situação que ela está ali não pode se mover. Eu fico preocupado com ela em se mexer, e ela ficar ruim e piorar. [...] Antes a pressão estava alta. Ela não tomava nenhum remédio. Só 
Vivências de homens acompanhantes de puérperas internadas na unidade de terapia... | 10

aqui que tomou. (H01)

Parte dos relatos citou as oscilações da pressão arterial e o transcorrer do procedimento cirúrgico como fatores geradores de ansiedades quanto ao estado de saúde do binômio. Essas narrativas sugerem que a mulher era vista pelos companheiros como um ser frágil e que precisava de cuidados mais complexos, repouso e de ajuda nas pequenas tarefas durante o puerpério, fase pouco conhecida pela maioria, o que pode gerar dúvidas.

\section{Cuidados com o recém-nascido frente às relações de gênero}

No momento em que os acompanhantes foram questionados sobre os cuidados com os recém-nascidos os depoimentos retratavam um homem-pai apreensivo porque nunca cuidou, ou mesmo, precisou cuidar dos filhos anteriormente, pois sempre havia uma figura feminina presente para executar essa função.

Para mim está sendo complicado, porque eu nunca cuidei. Eu tenho família, tenho dois filhos, mas nunca cuidei, nunca participei. E agora fui obrigado a participar, porque nenhuma das irmãs dela veio. Nenhuma. [...] A dificuldade é o trocar [fralda], porque nunca troquei, nunca dei banho. É isso! porque para ir a algum lugar [...] eu estou caminhando[...] Agora, o problema é trocar, dar o banho. (H07)

Já são três filhos, com essa quatro. Ainda não dei banho, mas não sei [risos]. Quando os outros filhos eram pequenos eu nunca tive que cuidar deles. Sempre [pausa] eu até falei para minha esposa, sempre eu fico mais receoso. (H05)

Até o momento está sendo um pouco difícil. E quando for mesmo na hora de trocar [a fralda], alguma coisa assim vai ser meio complicado. Já troquei fralda antes, mas desse tamanhinho não. E quem sempre acompanha é minha sogra. (H04)

Nos trechos dos depoimentos subjazem sentimentos de insegurança, receio e ansiedade ao cuidar do recém-nascido. Eles também desvelam um companheiro que encontra limitações para realizar tarefas que consideram de atribuição feminina e que comumente seriam executadas por outros familiares. 
Entretanto, apesar de terem sido observados casos em que o homem buscou se inserir nesse processo, verificou-se que alguns acompanhantes não demonstraram participação ativa nos cuidados com o recém-nascido num espaço socialmente visto como feminino. Evidenciou-se também que eles receberam e precisaram de ajuda das outras acompanhantes ou profissionais de saúde para cuidar, trocar a fralda, alimentação e cuidados de higiene com os recém-nascidos.

Está sendo uma experiência. Porque nunca tive outro filho. Não tive até agora dificuldades. Mas, na parte de trocar eu tive ajuda de uma mulher aqui, porque ele estava chorando e eu não estava conseguindo ajudar ele. Ela me ajudou. Quem está trocando é o pessoal daqui e minha cunhada quando vem. (H01)

A mãe dela [sogra] que dá o leite na canequinha, ela dá e eu fico olhando, prestando atenção. Mas se eu for dar também consigo. O rapaz [profissional], não sei o nome dele, disse que era melhor ficar mais mamando no peito da mãe, eles [gêmeos] estão fraquinhos, mas, conseguem mamar. Ele olhou e disse que estão bem. Para trocar [a fralda], e ela que troca também. (H03)

Observa-se, pelos relatos, que parte dos pais não estava preparada para assumir as inúmeras responsabilidades com relação aos cuidados com o recém-nascido. Notou-se, também, que a situação de saúde da sua companheira possibilitou novas experiências que poderiam interferir diretamente nas concepções de paternidade que cada homem construiu no decorrer de sua vida.

\section{Enfrentamentos dos homens durante o processo de internação da puérpera}

Quando os depoentes foram questionados sobre as principais adversidades que experimentaram durante o processo de hospitalização, alguns relataram a respeito da dificuldade para conciliar o sono e outros apontaram sobre a distância física entre a UTI e o berçário. Esse distanciamento entre os recém-nascidos e as companheiras foi considerado como um fator cansativo e desgastante para os homens.

Não é bom não. Porque tem que estar para cima e para baixo com a menina, ficar levando lá[na UTI] direto. (H02)

Eu estou cansado de estar lá e cá [...]. Me preocupo porque ela está lá, eu não 
Vivências de homens acompanhantes de puérperas internadas na unidade de terapia... | 12

estou vendo e ela não sabe aonde eu estou. Que nem agora, do jeito que ela foi para lá. Ela não sabe aonde é que eu estou ficando. Sabe que eu estou indo lá e voltando, mas não sabe o ambiente que eu estava. (H07)

A dificuldade é só dormir, mas eu não me preocupo não, já estou mais acostumado. Já trabalhei muitos anos virando noite, trabalhando em padaria (H08)

Nesse sentido, alguns participantes do estudo relataram momentos de dificuldades relacionados ao processo de aleitamento materno exclusivo (AME) e citaram estratégias sugeridas por terceiros para superar esses desafios. Desse modo, pressupõe-se que tenham sido propostas por profissionais de saúde do serviço ou até mesmo por outros acompanhantes de recém-nascidos. Percebe-se pelos depoimentos que houve a orientação quanto à demanda de tempo para oferta da mama para a criança.

Mandaram levar ele de 3 em 3 horas lá para onde está ela para alimentar, só isso. Eu fui levar ela meio dia para mamar, mas ela não quis porque estava dormindo, disseram para eu estimular ela, acordar quando for levar, daqui a pouco vou lá de novo. (H04)

Uma hora ela [criança] estava chorando muito, eu não estava entendendo o que era porque toda hora ela estava lá [na UTI] comia um pouquinho e não enchia a barriga. Quando chegava aqui, tornava a chorar de novo. [...] me disseram que a hora que ela chorasse era para levar para amamentação. (H07)

Outro aspecto de relevante citado pelos acompanhantes foi a preocupação com o restante da família que estava em casa, especialmente, os outros filhos que estavam naquele momento sem a assistência e sem o cuidado direto dos pais. Além disso, sinalizaram a necessidade do afastamento do trabalho para acompanhar a parceira.

Assim, o sentimento [pausa] além de estar preocupado com minha esposa e meu filho, fico pensando nos outros que estão lá também com a avó. Então, a gente fica dividido. Junta uma preocupação de um lado e do outro. E não sabe o que faz. (H08)

Até o momento minha preocupação é só com os [filhos] que estão em casa. 
(H04)

Eu parei o serviço e acompanhei ela, por causa dessa transferência senão perdia a vaga. $(\mathrm{H} 07)$

Nota-se, pelos relatos, que a hospitalização modificou a rotina familiar sendo necessário naquele momento o auxílio de outros membros da família. Alguns homens apontaram que receberam apoio da família para a realização dos cuidados com os demais filhos que estavam em casa e, ainda assim, essa situação pode gerar ansiedade e medo.

\section{Discussão}

Torna-se fundamental a comunicação efetiva da equipe de saúde com os familiares, sobretudo nos casos em que a mulher necessita de internação com cuidados em Unidades de Terapia Intensiva, minimizando sentimentos de medo e insegurança que o desconhecimento pode causar. Sabe-se que para uma assistência puerperal de qualidade e humanizada, é imperioso facilitar o acesso aos serviços de saúde e desenvolver condutas acolhedoras, livres de intervenções desnecessárias. Nessa direção, a equipe precisa considerar e estar sensível à família que vivencia uma gestação de alto risco, sobretudo na vigência de alguma síndrome hipertensiva, que pode ter um desfecho antes do previsto, muitas vezes com complicações maternas ou fetais. ${ }^{12}$

Nesse sentido, integrar o companheiro dando-lhe acesso às informações, respondendo perguntas e deixando-o diretamente envolvido na gestação, nos preparativos do parto e nos cuidados pós-parto pode motivar o envolvimento com o recém-nascido e contribuir positivamente na socialização de gênero. ${ }^{13}$ Ressalta-se que envolver o homem durante o parto favorece a vinculação precoce entre ele e o recémnascido. A presença paterna propicia a ativação de respostas emocionais protetivas. ${ }^{14}$

Ainda que complexo para alguns, a participação do homem durante todo esse processo gravídico-puerperal, enquanto esposo e/ou pai, pode ser vista, não apenas como obrigação legal, mas como direito reprodutivo. Percebe-se pelos relatos que a presença do pai como acompanhante da mulher passa a ser pouco valorizada pelos profissionais de saúde do serviço. Estudos destacam 
Vivências de homens acompanhantes de puérperas internadas na unidade de terapia... | 14

que essa vinculação do casal pode levar a uma discussão mais ampla sobre identidade social, bem como fortalecimento do exercício da paternidade ativa. ${ }^{13-15}$

Comumente, os parceiros experienciam sensações de insegurança e medo durante o préparto. Entretanto resguardam para si essa tensão e preocupação de como se dará o processo, com o intuito de não transparecer para parceira essa angústia. Fato que permanece até a constatação de que a mulher e o bebê estão livres de complicações e assim podem expressar seus sentimentos. ${ }^{14}$

Essa percepção de fragilidade pode sensibilizar o homem a uma mudança de atitude que antes limitava-se ao provimento do sustento da família e passa também a voltar-se para o cuidado da companheira e dos filhos. Essa experiência mais próxima do casal favorece repouso, distração, sentimento de segurança e apoio, bem como atenuação dos medos e angústias de ambos. ${ }^{16}$

É consenso entre os acompanhantes que nesse período de pós-parto torna-se imperativo atenção, repouso e cuidado para uma plena recuperação e prevenção de complicações à saúde da puérpera. Durante essa fase de mudanças biossocioculturais, os profissionais de saúde, os familiares e toda a rede de apoio envolvida devem estar atentos, pois, muitas vezes, no puerpério é comum sentimentos de vulnerabilidade e insegurança não serem entendidos verdadeiramente pela família. ${ }^{17}$ Nesse sentido, destaca-se a importância de a equipe de saúde, junto ao acompanhante, estimularem o autocuidado da mulher, buscando elevar a sua autoestima e melhorar o bem-estar do casal, estando sensíveis aos cuidados com a mente e com a imagem corporal da mulher. Esses esforços também podem evitar possíveis transtornos psicoafetivos envolvendo a família, considerando que neste período a mulher pode tornar-se mais vulnerável emocionalmente a apresentar sentimentos de ansiedade, dúvidas e inseguranças quanto as adequações familiares, autocuidado e cuidados com o recém-nascido. ${ }^{17}$

Nesse contexto familiar, muitas vezes, subjazem sentimentos de insegurança, receio e ansiedade paterna ao cuidar do recém-nascido. Em estudo realizado no setor do alojamento conjunto de um hospital do Ceará, sobre os cuidados prestados ao recém-nascido, pelo pai, 
observou-se que os sujeitos sinalizaram que na hora de banhar o bebê ou até mesmo pegá-lo no colo sentiram-se inseguros por medo de machucar. ${ }^{18}$

Historicamente, o cuidado é intrínseco à mulher, já que socialmente os papéis e funções dos atores no âmbito familiar são organizados por gênero e, a maioria das vezes, não atribui ao homem tarefas familiares e/ou domiciliares. Todavia no puerpério as mulheres necessitam de cuidados e essa função de cuidador pode ser transferida para o parceiro, podendo evitar algumas possíveis complicações e promovendo o bem-estar da sua companheira. O fato de poder contar com o apoio masculino para os cuidados com a criança, de si e até mesmo domiciliar, pode tornar a experiência do pós-parto mais tranquila para as puérperas. ${ }^{16}$

Corroborando isso, atualmente, as políticas de igualdade de gênero e conquistas no campo profissional das mulheres, dentre outros fatores, possibilitaram uma participação mais ativa do companheiro no cuidado com os filhos, favorecendo a vinculação precoce e a satisfação que uma relação íntima com o seu filho pode proporcionar. ${ }^{19}$ Nesse tocante, estudo sugere que os pais se organizam durante a gestação para assumirem os novos papéis de acordo com a criança e às suas exigências. Entretanto, esse processo culmina em mudança na vida do homem que para tornar-se pai e necessita apropriar-se de um novo status social e a uma sequência de novas responsabilidades. ${ }^{19}$

Culturalmente, o homem, por vezes, não é ensinado e preparado pela família, desde a infância, para aprender a respeito dos cuidados e das tarefas diárias que são vivenciadas no lar. Esse fato corrobora como um entrave social e cultural para a inclusão do pai nos cuidados diretos com a criança $\mathrm{a}^{20} \mathrm{e}$ isso foi evidenciado por meio de depoimentos dos participantes deste estudo. Paradigmas referentes às questões de gênero ainda são hegemônicos para parte significativa da população, diante disso, destaca-se, a relevância do homem estar sensibilizado e inserido nos cuidados pósparto. Esse envolvimento se configura em algo indispensável para a vinculação plena da tríade paimãe-filho, e não de ser encarada apenas como uma necessidade do binômio. ${ }^{16}$

Ao experenciar diretamente a prestação de cuidados ao bebê, como os banhos, trocas de 
Vivências de homens acompanhantes de puérperas internadas na unidade de terapia... $\mid 16$

fraldas e carinhos, o pai pode experenciar técnicas de comunicação com a criança diferentes das que a mãe desenvolve, contribuindo para vinculação e envolvendo na rotina familiar. Dessa maneira, o recém-nascido sabe reconhecer a figura paterna e aguarda o afago também por parte dele, ao mesmo tempo, esse homem adquire segurança e sente-se cada vez mais próximo do seu filho. ${ }^{14}$

Esse pai participativo pode ser desenhado na busca de conhecimento e do envolvimento de profissionais que vislumbrem e os assista em uma linha de cuidados masculinos voltadas à saúde sexual, reprodução e paternidade. Quando valorizado, incentivado e informado corretamente o homem pode sentir-se mais seguro e consciente da importância em assumir novas funções. ${ }^{13}$

A promoção e a educação em saúde têm papel fundamental, sobretudo com o enfermeiro como membro da rede de apoio ao casal e facilitador do processo gravídico-puerperal. Suas contribuições podem ser oportunizadas durante o planejamento reprodutivo, consultas de pré-natal, atividades coletivas, assistência ao parto e pós-parto, visitas domiciliares, acompanhamento do crescimento e desenvolvimento da criança e em distintas ocasiões de acesso à família. ${ }^{20}$

Nesse sentido, ainda que tardiamente, ressalta-se a oportunidade de incluir o homem como parte integrante da fase gestacional, parto e do pós-parto no ambiente hospitalar, aproveitando para ensiná-lo quanto aos cuidados com o recém-nascido, esclarecendo dúvidas e solucionando possíveis intercorrências durante esse período de desenvolvimento da paternidade. ${ }^{21}$ Ademais, dentre os benefícios disso verifica-se o apoio ao AME até os 6 meses após os pais serem informados quanto as vantagens psicológicas, biológicas e econômicas que o leite materno pode proporcionar ao binômio, favorecendo diretamente para que as mães também percebam a importância. ${ }^{22}$

Corroborando a isso, estudo aponta que puérperas que tiveram apoio de seus parceiros nos cuidados pós-operatórios, nas atividades domésticas e nos cuidados com o recém-nascido experimentaram um período de tranquilidade e conforto, sobretudo durante a amamentação. Também foi sinalizado que as elas se sentiram seguras, acolhidas, apoiadas e felizes durante o puerpério, o que preveniu o desgaste da mulher e as complicações pós-natal, além de contribuir 
para produção láctea e incentivar a amamentação exclusiva, o que favorece a vinculação familiar. ${ }^{15}$

Ressalta-se que facilitar a aproximação dos setores berçário e UTI poderia tornar o processo de aleitamento menos cansativo e mais prazeroso para os atores, tendo em vista que o envolvimento paterno na amamentação seja excepcionalmente importante para que ocorra a sua continuidade. Além disso, é fundamental o conhecimento dos pais quanto a importância e a necessidade desse suporte para a oferta do leite materno aos filhos. Nesse contexto, considera-se que as instituições de saúde devam estar preparadas com profissionais comprometidos com esse processo, capazes de acolher e apoiar o casal, colaborando com o sucesso da amamentação. ${ }^{23}$

Com relação a este aspecto, é preconizado encorajar o regime de aleitamento materno sob livre demanda, tendo em vista que amamentar com frequência e sem regularidade quanto ao tempo de permanência ou horários é intrínseco ao comportamento normal do recém-nascido, ressaltando sobre a atenção aos sinais de fome que o mesmo apresenta indicando a necessidade de alimentação. Estudo corrobora afirmando que o bebê deve mamar após sua solicitação, sob livre demanda, pois quanto mais vezes ele estiver sugando a mama, maior deverá ser a produção de leite materno, ressaltando que a duração de cada mamada pode diferenciar entre as crianças. ${ }^{24}$

Garantir a efetivação da amamentação durante os primeiros dias do puerpério é fundamental para o binômio mãe-bebê e gera inúmeros benefícios nutricionais, emocionais, econômicos e imunológicos. Nessa lógica, a qualificação dos pais e o fortalecimento das ações de promoção, incentivo e apoio ao AME são essenciais para a redução da morbimortalidade infantil e favorecer a adesão, além de estimular o protagonismo e a responsabilidade no cuidado com o recém-nascido. ${ }^{25}$

Reconhecendo essa importância, a instituição em que esta pesquisa foi realizada mantém o título da Iniciativa Hospital Amigo da Criança (IHAC) e deve propor-se ao fortalecimento e ao prolongamento da duração do aleitamento materno devido às repercussões positivas na saúde das crianças. Essa estratégia preconiza a participação paterna nesses cuidados, devendo o hospital garantir livre acesso e permanência da mãe ou do pai junto ao recém-nascido durante 24 horas. ${ }^{25-26}$ 
Vivências de homens acompanhantes de puérperas internadas na unidade de terapia... $\mid 18$

Outro ponto que vale ressaltar, é que muitas vezes, o principal provedor financeiro é o pai, o que pode dificultar o sustento da família quando o mesmo precisa abandonar o trabalho em detrimento do cuidado da mulher e recém-nascido. Essa separação do lar e das rotinas cotidianas pode gerar sentimentos e mudanças que influenciam no relacionamento da família, tornando-os vulneráveis e repercutindo negativamente em todos os envolvidos. ${ }^{27}$

O fato de o homem se dispor a estar presente nesse momento de dificuldade da sua companheira e vulnerabilidade do recém-nascido demonstra que aquela figura, membro distante, socialmente visto apenas como provedor financeiro e autoridade do lar pode ressignificar sua imagem. Ele pode ser percebido como um cuidador e ser valorizado enquanto pai pela sua companheira e pelos profissionais de saúde do serviço. Posto isso, existe a possibilidade de que o pai deixe de ser alheio afetivamente, tornando-se paulatinamente alguém disposto a expor suas necessidades afetivas e a iniciar no exercício do contato. ${ }^{28}$

Acredita-se que todo esse processo de hospitalização deva ser compartilhado por uma rede familiar de apoio tendo o companheiro como sustento dessa situação, seja no pré-parto, parto e pósparto. Quando toda a família está síncrona no cuidado e claramente orientada sobre o processo de hospitalização, tornam-se preparados para serem proativos e se autoajudarem. ${ }^{5}$

Observa-se que quando os atores estão devidamente esclarecidos, as orientações facilitam as ações de cuidado e consolidam a autoconfiança. A ausência de informações desde o pré-natal favorece o aparecimento de inseguranças em puérperas e seus companheiros, dificultando o enfrentamento e adaptação do casal a esse novo momento. Por isso, é necessário que os profissionais de saúde, em especial o enfermeiro, ofertem orientações oportunas aos cuidados e insiram o pai neste processo, de forma a minimizar as dificuldades vividas pelos cônjuges. ${ }^{16}$

Diante dessa realidade, a assistência realizada no período gravídico-puerperal deve ser focada em toda família, para além dos cuidados voltados apenas à mulher e a criança, de maneira que os serviços de saúde oportunizem ao homem a sua participação por meio do aprendizado vindo 
da educação em saúde e da troca de experiências. São primordiais profissionais sensíveis a importância paterna e o seu impacto positivo na saúde de toda a família, reconhecendo que o homem possui demandas diferentes das femininas e uma maneira própria de envolvimento no processo. Todavia, estudo indica que os serviços de saúde ainda não estão prontos para atender às necessidades dos homens que buscam o exercício da paternidade ativa e relatam como os principais entraves a oferta restrita de grupos educativos, falta de divulgação das ações e estímulo insuficiente à participação paterna na comunidade. ${ }^{29}$

Frente a isso, é oportuno que os serviços estejam disponíveis às modificações socioculturais da sociedade, que percebem o homem como um coparticipante do processo e não aquele que pode dificultar o trabalho dos profissionais. Portanto, as práticas de educação em saúde devem promover a inclusão do companheiro e outros familiares da mulher nesse processo contínuo de aprendizado. ${ }^{30}$

Destaca-se, como limitações desse estudo, a carência de publicações referentes ao tema nos últimos anos, e sugere-se novos estudos que abarquem os atuais arranjos familiares, buscando avaliar diferentes perspectivas para além do modelo heteronormativo dentro das instituições familiares, tendo em vista que o homem gradativamente deixa de ser mero espectador e torna-se protagonista ao lado de sua companheira durante o processo de gestar.

\section{Conclusão}

Este estudo demonstrou que os participantes experenciaram dificuldades de comunicação com os profissionais que prestavam assistência no serviço já que não compreendiam as reais condições de saúde e os riscos de complicações durante a hospitalização de suas companheiras. As informações eram superficiais ou pouco detalhadas, o que tornava difícil o entendimento do homem durante todo esse processo. Essas falhas de comunicação geravam sentimentos de ansiedade e insegurança durante o distanciamento entre a tríade mãe-pai-filho, podendo comprometer também todo o processo de vinculação essencial nesse período. 
Vivências de homens acompanhantes de puérperas internadas na unidade de terapia... $\mid 20$

Quanto ao homem como cuidador da mulher, percebeu-se que a preocupação com relação ao tipo de parto e o medo das oscilações da pressão arterial estiveram presentes na maioria dos relatos. A parceira era vista como um ser frágil e que demandava cuidados maiores durante o pós-parto. Dessa maneira, em meio a um contexto de aflições, incertezas e experenciando ansiedades, as ações voltadas para o cuidado direto da puérpera foram pouco referidas.

Quanto aos cuidados com o recém-nascido, percebeu-se um homem que nunca cuidou ou precisou ter essa função anteriormente. A maioria citou uma mulher que desenvolvia esse papel no seu contexto familiar e, por isso, apresentou limitações quando esteve diante dessa demanda durante a internação de sua companheira, dificultando sua participação ativa nos cuidados e desenvolvimento da paternidade. Desse modo, foi perceptível nos relatos que a hospitalização modificou todo o ritmo familiar, cuidado com os filhos, dificuldade para o sustento financeiro e afastamento do trabalho, sendo inevitável o auxílio de uma rede de apoio para compartilhar as dificuldades e tarefas que são demandadas durante esse momento.

Ressalta-se que, os profissionais de saúde, principalmente os enfermeiros obstetras, devem estar sensíveis para a importância do parceiro, incentivar a sua vinculação e elaborar estratégias educacionais para inserção e participação ativa do companheiro durante o período gravídicopuerperal, oportunizando benefícios à mulher, ao filho e a si mesmo. Frente a isso, por meio dessa pesquisa pode-se trazer também contribuições para sensibilizar os profissionais de saúde que assistem à família a desenvolverem condutas acolhedoras e livres de julgamentos e/ou preconceitos. Esse estudo oportuniza reflexões sobre o papel do homem no contexto de hospitalização devido a gestação de alto risco, considerando suas singularidades e gerando práticas humanizadas, o que pode repercutir positivamente na saúde física e mental dos familiares envolvidos. 


\section{Referências}

1. Montenegro CAB, Rezende Filho J. Obstetrícia Fundamental. 13를 ed. Rio de Janeiro: Guanabara Koogan; 2017.

2. Oliveira GS, Paixão GPN, Fraga CDS, Santos MKR, Santos MA. Assistência de enfermeiros na síndrome hipertensiva gestacional em hospital de baixo risco obstétrico. Rev Cuid (Bucaramanga). 2017;8(2):1561-72. doi: $10.15649 /$ cuidarte.v8i2.374

3. Ferreira MBG, Silveira CF, Silva SR, Souza DJ, Ruiz MT. Assistência de enfermagem a mulheres com pré-eclâmpsia e/ou eclampsia: revisão integrativa. Rev Esc Enferm USP. 2016;50(2):320-30. doi: 10.1590/S0080-623420160000200020

4. Ministério da Saúde (BR), Secretaria de Vigilância em Saúde. Boletim Epidemiológico nº 20. Mortalidade materna no Brasil. Brasília (DF): Secretaria de Vigilância em Saúde; 2020 [acesso em 2020 jul 10];51(20):21-7. Disponível em: https:/portaldeboaspraticas.iff.fiocruz.br/wp-content/uploads/2020/06/Boletimepidemiologico-SVS-20-aa.pdf.

5. Ferreira SV, Soares MC, Cecagno S, Alves CN, Soares TM, Braga LR. Cuidado de enfermagem na ótica das gestantes de alto risco. Rev Fam Ciclos Vida Saúde Contexto Soc [Internet]. 2019 [cited 2020 May 01];7(2):14350. Available from: http://seer.uftm.edu.br/revistaeletronica/index.php/refacs/article/view/3410

6. Ministério da Saúde (BR). Amigo, gravidez, parto e cuidado também são coisas de homem: lei do acompanhante no 11.108/05 [Internet]. Brasília, DF: Ministério da Saúde; 2014 [acesso em 2018 abr 08]. Disponível em: https://pesquisa.bvsalud.org/bvsms/resource/pt/mis-37425

7. Abade F, Romanelli G. Paternidade e paternagem em famílias patrifocais. Rev Estud Fem. 2018;26(2):e50106. doi: 10.1590/1806-9584-2018v26n250106

8. Zanatta E, Pereira CRR, Alves AP. A experiência da maternidade pela primeira vez: as mudanças vivenciadas no tornar-se mãe. Pesqui Prát Psicossociais [Internet]; 2017 [acesso em 2018 maio 06];12(3):1-16. Disponível em: http://pepsic.bvsalud.org/scielo.php?script=sci_arttext\&pid=S1809-89082017000300005

9. Região e Redes: Caminho da universalização da saúde no Brasil. Relatório: Petrolina e Juazeiro: profissionais de saúde. Relatório regional: pesquisa política, planejamento e gestão das regiões e redes de atenção à saúde no Brasil [Internet]; 2017 [acesso 2018 jun 22]. Disponível em: http://www.resbr.net.br/wpcontent/uploads/2017/06/dossie_petrolina_juazeiro_03_profissionais_de_saude.pdf

10. Minayo MCS. Amostragem e saturação em pesquisa qualitativa: consensos e controvérsias. Rev Pesqui Qual [Internet]. 2017 [acesso em 2020 ago 18];5(7):01-12. Disponível em: https://editora.sepq.org.br/rpq/article/view/82/59

11. Bardin L. Análise de conteúdo. São Paulo: Edições 70; 2016.

12. Amorim FCM, Neves ACN, Moreira FS, Oliveira ADS, Nery IS. Perfil de gestantes com pré-eclâmpsia. Rev Enferm UFPE On Line [Internet]. 2017 [cited 2020 Aug 08];11(4):1574-83. Available from: 
Vivências de homens acompanhantes de puérperas internadas na unidade de terapia... | 22

https://periodicos.ufpe.br/revistas/revistaenfermagem/article/view/15225

13. Gomes B, Albernaz L, Ribeiro CRS, Moreira MCN, Nascimento M. Lines of male care geared to sexual health, reproduction and paternity. Ciênc Saúde Colet. 2016;21(5):1545-52. doi: 10.1590/141381232015215.26842015

14. Matos MG, Magalhães AS, Féres-Carneiro T, Machado RN. Construindo o vínculo pai-bebê: a experiência dos pais. Psico USF [Internet]. 2017 [acesso em 2020 maio 08];22(2):261-71. Disponível em: https://www.scielo.br/pdf/pusf/v22n2/2175-3563-pusf-22-02-00261.pdf

15. Cavalcanti TRL, Holanda VR. Participação paterna no ciclo gravídico-puerperal e seus efeitos sobre a saúde da mulher. Enferm Foco [Internet]. 2019 [acesso em 2020 mai 08];10(1):93-8. Disponível em: http://revista.cofen.gov.br/index.php/enfermagem/article/view/1446.

16. Silva EM, Marcolino E, Ganassin GS, Santos AL, Marcon SS. Participação do companheiro nos cuidados do binômio mãe e filho: percepção de puérperas. Rev Pesqui Cuid Fundam. 2016;8(1):3991-4003. doi: 10.9789/2175-5361.2016.v8i1.3991-4003

17. Barbosa EMG, Rodrigues DP, Sousa AAS, Fialho AVM, Feitosa PG, Landim ALP. Necessidades de autocuidado no período pós-parto identificadas em grupos de puérperas e acompanhantes. Rev Enferm Atenção Saúde. 2018;7(1):166-79. doi: 10.18554/reas.v7i1.1921

18. Mendonça FAC, Nations MK, Sampaio LRL, Coutinho GGR, Menezes GB, Nascimento JC, et al. Cuidados prestados pelo pai ao recém-nascido no alojamento conjunto do Hospital Gonzaguinha de Messejana. In: Atas do 50 Congresso Ibero-Americano em Investigação Qualitativa. 2016 jul 12-14; Porto (Portugal): CIAIQ 2016; 2016 [acesso em 2020 jul 18];2:1570-8. Disponível em: https://proceedings.ciaiq.org/index.php/ciaiq2016/article/view/916/900

19. Santos S, Ferreira CF, Santos CSS, Nunes MLT, Magalhães JAA. Experiência paterna frente ao diagnóstico de malformação fetal. Bol Acad Paul Psicol [Internet]. 2018 [acesso em 2020 maio 08];38(94):87-97. Disponível em: http://pepsic.bvsalud.org/scielo.php?script=sci_arttext\&pid=S1415-711X2018000100009

20. Gutmann VLR, Silva CD, Fazio IA, Mota MS, Acosta DF. Cuidados com o recém-nascido: a contribuição do pai no aleitamento materno. Vittalle. 2018;30(2): 21-30. doi: 10.14295/vittalle.v30i2.7945

21. Ministério da Saúde (BR), Secretaria de Atenção à Saúde, Departamento de Ações Programáticas Estratégicas. Guia do pré-natal do parceiro para profissionais de Saúde [Internet]. Brasília (DF): Ministério da Saúde; 2018 [acesso em 2020 dez 18]. Disponível em: http://bvsms.saude.gov.br/bvs/publicacoes/guia_pre_natal_profissionais_saude.pdf?fbclid=IwAR3XA1OEMr0VCEJR_BN-1J3R0Jmivvcogtv-wB5nZ8F3DznPsmHUWoav_w

22. Santos EM, Ferreira VB. Pré-natal masculino: significados para homens que irão (re)experienciar a paternidade. Rev Funec Cient. 2016;5(7):62-78. doi: 10.24980/rfcm.v5i7.2338 
23. Lima JP, Cazola LHO, Pícoli RP. A participação do pai no processo de amamentação. Cogitare Enferm. 2017;22(1):01-7. doi: 10.5380/ce.v22i1.47846

24. Leite MGB, Lima RF, Formigal WAM, Targino MVP, Soares JG, Vasconcelos LPF, et al. Aleitamento materno exclusivo: olhar das nutrizes do interior Paraibano. Rev Eletrônica Acervo Saúde. 2018;17(55):01-8. doi: $10.25248 /$ reas.e55.2019

25. Fazio IA, Silva CD, Acosta DF, Mota MS. Alimentação e aleitamento materno exclusivo do recémnascido: representação social do pai. Rev Enferm UERJ. 2018;26(26740):01-7. doi: 10.12957/reuerj.2018.26740

26. Lamounier JA, Chaves RG, Rego MAS, Bouzada MCF. Iniciativa hospital amigo da criança: 25 anos de experiência no Brasil. Rev Paul Pediatr. 2019;37(4):486-93. doi: 10.1590/1984-0462/;2019;37;4;00004

27. Costa AR, Nobre CMG, Gomes GC, Nornberg PKO, Rosa GSM. Sentimentos gerados na família pela internação hospitalar da criança. J Nurs Health. 2019; 9(2):e199206. doi: 10.15210/jonah.v9i2.14012

28. Rêgo RMV, Souza AMA, Rocha TNA, Alves MDS. Paternidade e amamentação: mediação da enfermeira. Acta Paul Enferm. 2016;29(4):374-80. doi: 10.1590/1982-0194201600052

29. Balica LO, Aguiar RS. Percepções paternas no acompanhamento do pré-natal. Rev Atenção Saúde. 2019;17(61):114-26. doi: 10.13037/ras.vol17n61.5934

30. Spindola T, Penna LH, Lapa AT, Cavalcanti ALS, Silva JMR, Santana RSC. Período pós-parto na ótica de mulheres atendidas em um hospital universitário. Enferm Foco. 2017;8(1):42-6. doi: 10.21675/2357707X.2017.v8.n1.847

Editora Científica Chefe: Cristiane Cardoso de Paula

Editora associada: Graciela Dutra Sehnem

\section{Autor correspondente}

Marianna dos Santos Araújo

E-mail: mariannasaraujo@hotmail.com

Endereço: Rua Américo Tanury, 575, Jardim Flórida, Juazeiro-BA

CEP: $48900-584$

\section{Contribuições de Autoria}

1 - Marianna dos Santos Araújo

Concepção ou desenho do estudo/pesquisa; Análise e/ou interpretação dos dados; Revisão final com participação crítica e intelectual no manuscrito. 
Vivências de homens acompanhantes de puérperas internadas na unidade de terapia... | 24

\section{2 - Mônica Cecília Pimentel de Melo}

Concepção ou desenho do estudo/pesquisa; Análise e/ou interpretação dos dados; Revisão final com participação crítica e intelectual no manuscrito.

\section{3 - Lucivânia de Oliveira Costa}

Concepção ou desenho do estudo/pesquisa; Análise e/ou interpretação dos dados; Revisão final com participação crítica e intelectual no manuscrito

\section{4 - Lucineide Santos Silva Viana}

Revisão final com participação crítica e intelectual no manuscrito

\section{5 - Yane Tina Macêdo Pinto Santana}

Revisão final com participação crítica e intelectual no manuscrito

\section{Como citar este artigo}

Araújo MS, Melo MCP, Costa LO, Viana LSS, Santana YTMP. Vivências de homens acompanhantes de puérperas internadas na unidade de terapia intensiva por síndrome hipertensiva. Rev. Enferm. UFSM. 2021 [Acesso em: Anos Mês Dia]; vol.11 e47: 1-24. DOI: https://doi.org/10.5902/2179769248306 